\title{
List of graphs
}

3.1: Daily new confirmed cases in Ireland (rolling 7-day average), March 2020

3.2: $\quad$ The three waves of COVID-19 in Ireland

3.3: Advanced COVID-19 doses purchased globally

4.1: $\quad$ Cumulative COVID-19 deaths, October 2020

4.2: COVID-19 death evolution in the period between April and October 2020

4.3: New Zealand: 7-day rolling average of new cases February-May 2020

4.4: Flights and COVID-19 cases in New Zealand, February-December 2020

4.5: 7-day rolling average of daily new confirmed cases per million people in Ireland and Germany, March 2020-March 2021

4.6: Flights and COVID-19 cases in Germany, February-December 2020

4.7: Flights and COVID-19 cases in Ireland, February-December 2020

4.8: Daily confirmed COVID-19 cases per million people in the US and Canada, March 2020-June 2021

4.9: $\quad$ Flights and COVID-19 cases in Canada, February-December 2020

4.10: International and domestic flights and COVID-19 cases in the US

4.11: India 7-day rolling average of cases, January 2020-May 2021

4.12: Daily confirmed COVID-19 in South Africa, April-September 2020

4.13: Percentage vaccinated against COVID-19, May 9, 2021 
